This is an original manuscript of an article published by Taylor \& Francis in the Journal of Library \& Information Services in Distance Learning on 5 September 2018, available online: https://www.tandfonline.com/doi/full/10.1080/1533290X.2018.1498621

\title{
Using a Library Learning Object Repository to Empower Teaching Excellence for Distance Students
}

\author{
Lisa Becksford \\ Stefanie Metko \\ Virginia Tech
}

\begin{abstract}
In 2015, in response to the findings of an online learning needs assessment, two librarians and a web developer began creating a library learning objects repository. This repository would ensure that distance learners were receiving excellent library services, including library instruction. The team worked with the libraries' digital media specialist to create an attractive interface and consulted with one of the library's metadata specialists to create metadata that would help to make the repository easy to search and browse. Further plans include wide-scale sharing with the larger library community and continued growth in the number and types of objects in the repository.
\end{abstract}

\section{Introduction}

Virginia Tech is a comprehensive, public, land-grant university with over 33,000 students and is the state's leading research university, with locations across the state and online. Building off the university's three primary mission areas of learning, discovery and engagement, the University Libraries at Virginia Tech have sought to increase engagement on a local, regional, national, and global level through a number of reorganizations aimed at positioning the Libraries to be deeply embedded in University strategic initiatives. The Libraries are uniquely situated within the teaching and learning enterprise at the University and have been growing in their leadership within the educational content development space, as well as in the areas of library instructional design, library online learning services, and the curation and preservation of educational materials. In addition, the University underwent a massive structural and strategic reorganization beginning in late 2014, placing greater emphasis on metrics-based decision making and on connecting outcomes-based assessment to student and faculty success indicators. Secondary outcomes were also established: personal development, workforce development, knowledge creation, economic development, and embedded societal impact. The Libraries were charged with mapping their own strategic growth areas to these success indicators.

Odyssey (http://odyssey.lib.vt.edu/) is the library learning object and educational content repository developed and maintained by the University Libraries at Virginia Tech. In the planning stages since spring 2014, Odyssey formally launched to the Virginia Tech campus community in August 2017. Odyssey was created in response to campus changes and to fill specific needs within Virginia Tech's library and campus: content that was modular and 
adaptable to a variety of contexts, content that could easily be added to LibGuides and Canvas, and a platform that made the content easy to find and gathered it into one place. Additionally, Virginia Tech, a land-grant institution, increasingly views itself as a global land-grant university, one that extends its land-grant mission beyond Virginia to the entire world (Virginia Tech, 2015). To this end, Odyssey contains open educational resources that can support library instruction not just at Virginia Tech, but around the world. This case study will describe the development of Odyssey as well as applications to other long-term online learning projects.

\section{Literature Review}

Definitions of learning objects abound. Wiley (2002), in a widely-cited definition, defines a learning object as "any digital resource that can be reused to support learning” (p. 6). Because this definition is so broad, others have crafted more specific definitions. Weller (2007), for instance, notes that a learning object "addresses a clearly identifiable topic or learning outcome" (p. 27). Laverde, Cifuentes, and Rodríguez (2007) and Becker (2010) state that learning objects are self-contained. These definitions emphasize the learning object's digital nature, purpose in learning, and potential for reuse. This reusable, modular nature of learning objects distinguishes learning object repositories from other digital repositories (Cervone, 2012). A learning object repository, then, "is an electronic database that accommodates a collection of small units of educational information or activities that can be accessed for retrieval and use” (Lehman, 2007, p. 60-61).

As higher education has increased its online learning offerings, libraries have turned to the creation of learning objects as a way to increase students' engagement with the library (Kammerlocher, Couture, Sparks, Harp, \& Allgood, 2011). Once a learning object is created, it can be reused in a variety of contexts at the point of need, facilitating alternative approaches to library instruction, such as the flipped classroom (Becker, 2010; Shank, 2003). Learning objects can also help libraries scale their instruction to meet the needs of increasing numbers of students, even with a limited number of instruction librarians (O’Neill, 2017).

There are several well-known learning object repositories featuring learning objects suitable for library instruction. MERLOT (https://www.merlot.org), for example, produced by the California State University system, features a wide range of learning objects from a variety of disciplines, including a Library and Information Services Community Portal with objects that can be used for library instruction. Likewise, OERCommons (https://www.oercommons.org/), an expansive collection of open educational resources, contains information literacy resources and a Library and Information Literacy group where such resources can be found. Other repositories are dedicated exclusively to library and information science, such as the ACRL Instruction Section's PRIMO (http://primodb.org/). PRIMO features librarian-created, peer-reviewed teaching materials on a variety of information literacy-related topics. Other libraries are creating and maintaining their own learning object repositories to accomplish goals particular to their institutions (O’Neill, 2017).

\section{Uncovering the Community's Needs}

When the authors, as well as a web learning environments application developer, joined the University Libraries at Virginia Tech in 2015, they were tasked with creating an online learning platform. The goal was to deploy high-quality library learning materials for new and 
existing initiatives to meet the needs of both online and distance students and new general education courses and other curricular initiatives, such as digital literacy and ePortfolio. The original visionaries of the platform had by that time left Virginia Tech, so the authors were essentially beginning the planning process all over again. As they began to plan, they realized that there was much that was not known about the state of online learning at Virginia Tech, let alone the libraries. Therefore, in October 2015, the authors embarked on a wide-scale needs assessment to learn about current library use in online classes, as well as the needs of online and extended campus students.

Since Virginia Tech is a decentralized campus with multiple locations, and several units at the main campus were charged with what seemed like overlapping student and faculty clientele, the authors focused their efforts on identifying duplication as well as gaps in service. This needs assessment confirmed their impression that there was no existing learning object repository on campus that could serve the needs of library engagement, particularly as that engagement connected to new initiatives and services. Learning objects created within the library were scattered among a variety of platforms, including LibGuides, individual and library YouTube channels, the learning management system, and the library website. In addition, what they found solidified their commitment to creating a platform to support online learning in all its forms. Institutional data indicated that the number of students taking online classes had increased steadily in recent years, more than doubling from 2006-2016. This number included both students based at the main campus in Blacksburg and students based elsewhere taking online classes. When asked whether faculty required the use of the library for online classes, both students (64.7\%) and faculty (74.9\%) said that the use of library resources was not required for online classes. When students were asked why they did not use library resources in their online classes, $71 \%$ indicated that they were not required to use them, as would be expected, but $13.5 \%$ also indicated that they did not know how to use library resources. Faculty articulated a number of needs for a learning objects repository: it should be user friendly for both faculty and students, be visually appealing, contain resources that were relevant to their teaching, and be easy to search and browse. A learning objects repository would be a way not only to support these students with tutorials and other content that would help them learn to use the library resources but also to increase the visibility of library resources by making it easy to integrate training and tutorials into online classes.

\section{Choosing a Platform}

When it was time to begin developing the platform in spring 2016, the authors worked with their library's web learning environments application developer to build a repository that was responsive to the needs uncovered in the needs assessment. As a first step, existing platforms and repositories were considered, beginning with OER Commons. This site is well known and would have given increased visibility to the content the authors created. However, OER Commons was soon rejected as an option: it would have required paying a yearly fee, and OER Commons would only be able to index an existing repository, not create one from scratch. In addition, since some of the content would need to be created specifically for programs and websites unique to Virginia Tech, it would not necessarily be useful to other educators and therefore not completely suited for inclusion in OER Commons.

The authors also considered adding learning objects to Virginia Tech's institutional repository, VTechWorks, and building a forward-facing page that would pull the learning objects 
from VTechWorks. VTechWorks was initially appealing because using it would have eliminated the need to develop a repository. However, in an exploratory conversation with the repository manager, the authors realized that VTechWorks was not the most appropriate place for the learning objects. For starters, learning objects are updated often, and an out-of-date object would likely need to be replaced without previous versions being kept or a new entry created, in contrast to VTechWorks' file persistence. In addition, the addition of learning objects to the existing repository did not fit VTechWorks' goals, and the authors realized that they wanted to have more control over the repository than they would have had by using an existing platform. Finally, using VTechWorks would not really save much time, as the user interface would still need to be built.

Once these existing repositories were decided against, the authors considered possibilities for developing their own. The major platforms considered were DSpace, Fedora/Hydra, and Omeka, as well as the possibility of building a repository from scratch. They decided against developing a repository from scratch since it would have required a considerable outlay of time and energy. Ultimately, Omeka was chosen. Omeka is easy to install and works with a common server architecture. In addition, it has easy-to-use plug ins, such as the ability to integrate with Shibboleth so that the university's single sign on could be used for administrator log ins. The interface also allowed the customization of other features, such as custom data types, without having to do custom coding. Omeka was also ideal because file persistence was not needed since the learning objects are likely to be updated frequently. It also has an easy-to-use back end which makes it simple for librarians to be able to add most items to it, rather than having to ask the web developer to add items to it on the librarians’ behalf.

As with any technology, not everything about Omeka is perfect. Because it's so widespread and runs on a technology that's ubiquitous on the web, it's a potential target for security issues. However, in the authors' experience, bugs do get fixed quickly. Omeka was designed primarily for images, so incorporating html5 and videos has been somewhat complicated. While librarians are able to add most content themselves, any Articulate Storyline products must be sent first to the web developer, who adds them to the server and creates a record featuring a screenshot of the tutorial. Clicking on that images will bring up the link to the tutorial in a new window. Videos are pulled from the Odyssey YouTube page, which allows the use of YouTube's captioning features. The use of YouTube also allows easy integration with the LibGuides platform. It was also necessary to create some custom metadata options, since Odyssey’s needs as a learning object repository were different from other repositories. Additionally, Omeka's built-in search function was quirky (for instance, initially, a search string had to have at least 4 characters, which meant that a search for APA would not bring up any of APA citation content), so the web developer created a workaround. The built-in filtering system is part of the search functionality, so when it was determined that a standalone filtering system was needed, that had to be built. Despite these downsides, Omeka has able to give what was needed for Odyssey. Omeka also has the potential to allow the expansion of Odyssey in the future. A learning technologies integration (LTI) is currently in the works that will allow Odyssey to integrate with the Canvas learning management system, thereby enabling users to integrate learning objects into their classes easily. Additionally, OmekaS could give the potential to make different portals for different users, such as Virginia Tech and non-Virginia Tech users, easily directing them to the content they are looking for. 


\section{Features of Odyssey}

All those involved in the creation of Odyssey wanted it to be both visually appealing and easy to use, so the authors worked with others in the library on the visuals and the metadata. A custom Omeka theme was used, and the authors worked with the library's digital media specialist to create a unique visual look (Figure 1). Since Omeka is frequently used in libraries, it's well documented, and the VT Libraries' system administrators have experience working with it already, simplifying the theming process. Because a visually appealing repository would not be very practical if its items could not be easily found, the authors consulted with the libraries' data curator on the metadata and tagging system. In addition to Omeka's standard Dublin Core metadata, an additional field of item type was added to differentiate the item type from the file type. In addition to these chosen metadata fields, Omeka's tagging system and the ability to create collections were also implemented. Initially, each tag was created as needed when an item was uploaded, but after the repository grew to about 20 items, it became obvious that this lack of standardization was making the tagging system inefficient. In addition, user-created tags tended to be ones that would make sense only to those within the Virginia Tech community, such as course abbreviations unique to Virginia Tech. Once the tags were standardized and some best practices for their creation were developed, the system became much more useful. Finally, Omeka's collection feature made it easy to curate groups of objects for different users, such as first-year writing. Since each collection has its own link, it's easy to direct faculty and students to resources that they will likely find helpful.

Another element that was important to consider was accessibility. It was essential to create something that could be used by everyone, regardless of ability, so it was important that the website as well as each learning object was accessible. The website itself is mindful of the needs of those using screen readers, and videos, which are pulled in from the Odyssey YouTube channel, are captioned. Articulate Storyline tutorials use both captions and alt text for images. The goal of making everything accessible is one that the authors are still moving towards; as they learn more about accessibility and add new types of content to Odyssey, they are likely to run into new challenges and plan to continue learning about accessibility and working with experts both within the library and on Virginia Tech's campus.

In addition to making the content accessible, the authors wanted to make it as open as possible. All items that are created have their Creative Commons licensing information visible on the object, and when items are added to the repository, their licensing information is included in the metadata. The majority of the items in Odyssey are licensed with the CC-BY designation, and others are welcome to adapt and remix the content as long as they follow the guidelines of the CC-BY license.

In addition to creating robust metadata, Odyssey needed to be easily found by the Virginia Tech community. While having a repository would make it easier for librarians to direct users to the content and to integrate it into Canvas courses and LibGuides, the authors also wanted users to be able to discover it on their own. Since the Virginia Tech Libraries' main library website was being redone in summer 2017, the authors took that opportunity to ask the web team to add a link from the library's homepage, which they did. This link has helped to direct new traffic to Odyssey, both from those who stumble upon it and those who do not necessarily remember the URL but do remember how to navigate to it. 


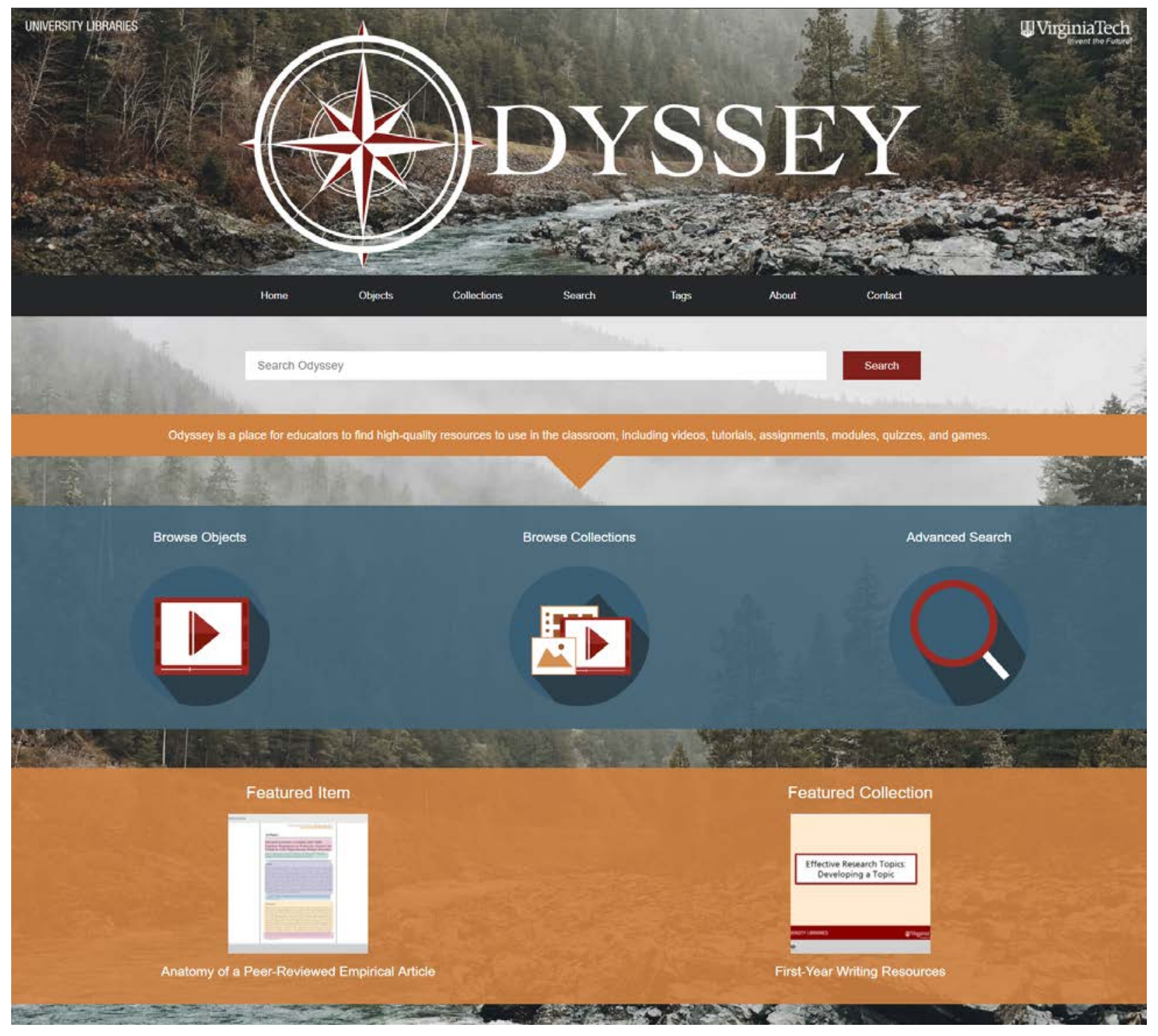

Figure 1. The Odyssey Home Page.

\section{The Future of Odyssey}

The authors' immediate plans for Odyssey include continuing to add new content, particularly in areas where our library instruction is growing, such as digital literacy. Their unit in the library is embarking on a curriculum mapping project that will demonstrate areas where it's possible to increase students' interaction with library instruction, particularly through the creation of online content. In addition, Virginia Tech has long-range plans to build its programs at extended campuses, so additional online content could help to reach students there. They also 
hope to soon be able to implement the LTI that would enable easy integration of objects from Odyssey to Canvas.

\section{Conclusion}

While not every library will find it necessary to create a learning objects repository for their own library, there are several lessons to be learned. First, the need for collaboration is crucial when setting out on a project of this magnitude. Odyssey would not have been possible without the assistance of others in the library, such as the web developer, media design specialist, and data curator. It was important that the authors recognize their own limitations and reach out to those within the library who could help further the project.

While embarking on a large needs assessment may seem like the right place to start, it may also be wise to consider the landscape. For example, in the case of this project, the campus was changing so rapidly that the pace in which the changes were happening couldn't keep up with the pace at which the researchers could process the data and act upon it. In addition, by the time partners are found, miscommunication and other pitfalls could damper any low hanging fruit that might have been uncovered earlier had a different approach been taken.

However, embarking on a comprehensive needs assessment did uncover very clear gaps in service that existed, particularly for distance and online students. Careful consideration of the needs of the population could inform decisions regarding content creation, the scope of the project, and ultimately whether it's better to curate resources from other sources or if there is truly a need to develop something new. In the authors' case, there truly was a need, not only on the campus but also within the field for new content to be developed. There was also an equal need for that content to be openly shared within the field so that others could build on that work in a way that could have an impact beyond Virginia Tech.

Another key takeaway is that a project like this will not happen overnight. Careful planning is the first step. Identifying a team's capacity to sustain the project, administrative buyin, the political landscape on a campus, and other factors that influence long-term success should be considered. This project took nearly two years from the planning process to the implementation phase and it is still a work in progress. It took both hours of work and passion for that work. Flexibility, both in terms of mindset as well as the schedule for accomplishing goals is key to a successful design, implementation, and maintenance of a project such as Odyssey.

Lastly, knowing the community and their needs and setting realistic goals for the project will go a long way in seeing the project to completion. It is important to note that it became clear to the authors towards the later stage of the project that it wasn't possible to be all things to all people. In fact, the project became more meaningful with focused intent. In the planning process, setting time aside to think through scope and audience will alleviate later concerns and help the project to be successful. 


\section{References}

Becker, B. W. (2010). Digital learning object repositories. Behavioral \& Social Sciences Librarian, 29(1), 86-88. doi:10.1080/01639260903571898

Cervone, H. F. (2012). Digital learning object repositories. OCLC Systems \& Services: International Digital Library Perspectives, 28(1), 14-16. doi:10.1108/10650751211197031

Kammerlocher, L., Couture, J., Sparks, O., Harp, M., \& Allgood, T. (2011). Information literacy in learning landscapes: Flexible, adaptable, low-cost solutions. Reference Services Review, 39(3), 390-400. doi:10.1108/00907321111161395

Laverde, A. C., Cifuentes, Y. S., \& Rodríguez, H. Y. R. (2007). Toward an instructional design model based on learning objects. Educational Technology Research and Development, 55(6), 671-681. doi:10.1007/s11423-007-9059-0

Lehman, R. (2007). Learning object repositories. New Directions for Adult and Continuing Education, 2007(113), 57-66. doi:10.1002/ace

O’Neill, J. L. (2017). Deploying a WordPress-based learning object repository to scale up instruction and effect a culture of sharing. Reference Services Review, 45(1), 131-140. doi:10.1108/RSR-10-2016-0059

Shank, J. D. (2003). The emergence of learning objects: The reference librarian's role. Research Strategies, 19(3-4), 193-203. doi:10.1016/J.RESSTR.2005.01.002

Virginia Tech (2015). Beyond boundaries: About. Retrieved from http://www.beyondboundaries.vt.edu/about.html

Weller, M. (2007). Learning objects, learning design, and adoption through succession. Journal of Computing in Higher Education, 19(1), 26-47. doi:10.1007/BF03033418

Wiley, D. A. (2002). Connecting learning objects to instructional design theory: A definition, a metaphor, and a taxonomy. In D. A. Wiley (Ed.), The Instructional Use of Learning Objects (pp. 3-23). Bloomington, IN: Agency for Instructional Technology and Association for Educational Communications \& Technology. 